\title{
Crónica de la Jurisprudencia del Tribunal de Justicia de la Unión Europea
}

\author{
Case Law Review of the Court of Justice of the European Union
}

\author{
David Ordóñez Solís \\ Magistrado y miembro de la Red de Especialistas en Derecho de la Unión Europea \\ del Consejo General del Poder Judicial
}

doi: http://dx.doi.org/10.18543/ced-62-2020pp189-223

Sumario: I. Introducción. La separación de poderes importa.II. Primera parte. Los desarrollos jurisprudenciales del derecho de la Unión Europea. 1. Los derechos fundamentales de la Unión. a) El alcance territorial del derecho al olvido en Internet: sentencia Google France / CNIL. b) El consentimiento y las cookies en Internet: sentencia Planet49. c) Los deberes de cesación de ilícitos en las redes sociales. d) La legalidad de los datos biométricos de trabajadores turcos. 2. El mercado único europeo: sentencia Airbnb Ireland. 3. El espacio de libertad, seguridad y justicia para los extranjeros. 4. La responsabilidad y el control en la transposición de las directivas. a) La sentencia $A W$, el 112 y la responsabilidad por mala transposición de la Directiva en Lituania. b) Bélgica condenada a una multa coercitiva por no informar sobre la transposición de una Directiva.-III. Segunda parte. La Jurisprudencia Europea provocada por los jueces españoles y sus efectos en el derecho interno. 1. El alcance de la inmunidad de los eurodiputados: sentencia Junqueras. 2. La protección social de los trabajadores en la jurisprudencia del Tribunal de Justicia. a) La aplicación de la Carta en materia social y la sentencia Ortiz Mesonero. b) La discapacidad en el ámbito laboral y la sentencia DW / Nobel Plastiques Ibérica. c) El empleo público temporal y el alcance de la Directiva 1999/70: auto Aragón Carrasco. d) El cálculo de la antigüedad de los trabajadores fijos discontinuos de la Agencia tributaria. e) La pensión de jubilación anticipada en España y la cotización en Alemania: sentencia Bocero Torrico. 3. La protección de los consumidores frente a las cláusulas abusivas y el poder del juez. 4. El sistema tributario español y el Derecho de la Unión Europea. a) La impugnación por las compañías eléctricas de los tributos y otras contribuciones. b) La devolución de aranceles abonados sin error imputable a las autoridades aduaneras de terceros países: sentencia Prenatal. 5. Los derechos derivados de la protección de variedades vegetales.-IV. Relación de las sentencias comentadas 


\section{Introducción. La separación de poderes importa}

El Tribunal Europeo de Derechos Humanos y el Tribunal de Justicia de la Unión Europea, Estrasburgo y Luxemburgo, los tribunales supranacionales en Europa, coinciden: la separación de poderes importa.

Como si Montesquieu hubiese resucitado, el Tribunal Europeo de Derechos Humanos ha observado que «la noción de la separación de poderes entre el ejecutivo y el judicial ha adquirido una creciente importancia en [nuestra] jurisprudencia» (sentencia de la Gran Sala del 6 de noviembre de 2018, Ramos Nunes de Carvalho e Sá c. Portugal, recursos n. ${ }^{\circ}$ 55391/13, $57728 / 13$ y 74041/13) y en los mismo términos lo ha repetido el Tribunal de Justicia en su sentencia A. K. y otros, C-585/18, C-624/18 y C-625/18, al garantizar firmemente la independencia judicial en Polonia: «conforme al principio de separación de poderes que caracteriza el funcionamiento de un Estado de Derecho, debe garantizarse la independencia de los tribunales frente a los poderes Legislativo y Ejecutivo».

En efecto, el Tribunal de Justicia en su formación de la Gran Sala dictó tres importantísimas sentencias sobre la independencia judicial en Polonia: en las dos primeras condenaba a Polonia por vulnerar la independencia de los jueces al rebajar su edad de jubilación y atribuir al Gobierno la facultad de prorrogar el mandato de algunos de ellos; y en la tercera contestaba una cuestión prejudicial remitida por el Tribunal Supremo en relación con la falta de independencia de la Sala Disciplinaria del Tribunal Supremo que conocía de la jubilación de los jueces polacos.

La primera sentencia, de 24 de junio de 2019, C-619/18, se refiere a la reducción de la edad de jubilación de los jueces del Tribunal Supremo polaco a los 65 años y a la facultad discrecional del Presidente de la República para conceder dos prórrogas.

Esta sentencia culmina un procedimiento por incumplimiento y se basa en el derecho fundamental a la tutela judicial efectiva para asegurar la independencia, la inamovilidad de los jueces nacionales.

A juicio del Tribunal de Justicia del derecho a la tutela judicial efectiva en los ámbitos cubiertos por el Derecho de la Unión derivan los principios de separación de poderes: «La necesidad de independencia de los tribunales, inherente a la función jurisdiccional, está integrada en el contenido esencial del derecho a la tutela judicial efectiva y del derecho a un proceso equitativo, que reviste una importancia capital como garante de la protección del conjunto de los derechos que el Derecho de la Unión confiere a los justiciables y de la salvaguarda de los valores comunes de los Estados miembros y, en particular, el valor del Estado de Derecho» (apartado 58).

Y continúa el Tribunal de Justicia que esta necesidad de independencia exige que las normas que rigen el régimen disciplinario y, por tanto, una 
posible remoción de quienes tienen la misión de juzgar, presenten las garantías necesarias para evitar cualquier riesgo de que dicho régimen pueda utilizarse como sistema de control político del contenido de las resoluciones judiciales» (apartado 77).

Además, la facultad discrecional de prórroga del Presidente de la República puede suscitar dudas legítimas en el ánimo de los justiciables, en lo que respecta a la impermeabilidad de los jueces afectados frente a elementos externos y en lo que respecta a su neutralidad con respecto a los intereses contrapuestos en los litigios de que puedan conocer (apartado 79).

La sentencia de 5 de noviembre de 2019, C-192/18, de la Gran Sala, vuelve a condenar a Polonia por haber establecido una edad de jubilación diferente para las mujeres (60 años) y los hombres (65 años) que desempeñan el cargo de juez o de fiscal y por haber dejado en manos del Ministro polaco de Justicia la facultad para autorizar o denegar la prórroga del ejercicio del cargo de juez hasta los 70 años de edad.

Por una parte, el Tribunal de Justicia consideró que la normativa polaca era discriminatoria y que, además, «la fijación de un requisito de edad para la jubilación diferente según el sexo no puede compensar las desventajas a las que están expuestas las carreras de las funcionarias, ayudándolas en su vida profesional y poniendo remedio a los problemas con los que pueden encontrarse durante su carrera profesional».

Por otra parte, el Tribunal de Justicia aplica su jurisprudencia anterior sobre la independencia de los jueces nacionales en el sentido de que «la necesidad de independencia exige que las normas que rigen el régimen disciplinario y, por tanto, una posible remoción de quienes tienen la misión de juzgar presenten las garantías necesarias para evitar cualquier riesgo de que dicho régimen pueda utilizarse como sistema de control político del contenido de las resoluciones judiciales». Ahora bien, en el caso de la legislación polaca controvertida el Tribunal de Justicia subraya que «la duración del ejercicio de la función jurisdiccional de los jueces de los tribunales ordinarios que de esta forma depende de la facultad puramente discrecional del ministro de Justicia es considerable, puesto que se trata de los últimos diez años de la carrera judicial en el caso de las mujeres y de los últimos cinco años en el caso de los hombres». Al mismo, tiempo el Tribunal de Justicia insiste en que la reforma polaca puede suscitar dudas legítimas en el ánimo de los justiciables en cuanto a que el nuevo sistema podría haber tenido en realidad la finalidad de permitir al ministro de Justicia, actuando discrecionalmente, apartar a determinados grupos de jueces en activo en los tribunales ordinarios polacos una vez alcanzaran la nueva edad ordinaria de jubilación y simultáneamente mantener en el cargo a otra parte de ellos.

La tercera es la referida sentencia A. K. y otros, la dicta la Gran Sala del Tribunal de Justicia el 19 de noviembre de 2019, en respuesta a tres reen- 
víos prejudiciales sobre la independencia de la Sala Disciplinaria creada en el Tribunal Supremo en la medida en que conoce de tres asuntos relativos a la jubilación de sendos jueces del Tribunal Supremo polaco decretada por el Consejo de la Judicatura de Polonia.

Aun cuando la sentencia se refiere y reitera principios establecidos en las dos sentencias anteriores contiene una importantísima jurisprudencia, derivada en particular de Estrasburgo, sobre la independencia y la imparcialidad de los jueces y, por ende, respecto de otros órganos constitucionales, en especial el legislativo y el ejecutivo.

El fundamento de la competencia del Tribunal de Justicia y de la jurisprudencia que desarrolla se apoya en el hecho de que la Sala Disciplinaria del Tribunal Supremo tenga que conocer de la aplicación de la Directiva 2000/78/CE relativa al establecimiento de un marco general para la igualdad de trato en el empleo y la ocupación, más en particular por lo que se refiere a la invocada discriminación por razón de la edad a jueces que habían cumplido los 65 años, y porque se aplica el artículo 47 de la Carta de los derechos fundamentales de la Unión sobre el derecho a la tutela judicial efectiva y a un juez imparcial, en particular, el derecho de toda persona a que su causa sea oída equitativamente por un juez independiente e imparcial.

El punto de partida es que «el Tribunal de Justicia debe velar por que su interpretación del artículo 47, párrafo segundo, de la Carta garantice un nivel de protección que respete el garantizado por el artículo 6 del CEDH, según lo interpreta el Tribunal Europeo de Derechos Humanos» (apartado 118).

A partir de aquí el Tribunal de Justicia va entreverando su jurisprudencia y la jurisprudencia de Estrasburgo con el fin de analizar, en relación con la Sala Disciplinaria del Tribunal Supremo, las competencias que se le atribuyen, su composición y las condiciones y reglas conforme a las cuales se nombró a los jueces que habían de integrarla, así como el contexto de su creación y los nombramientos.

Resumiendo su enjuiciamiento, el Tribunal de Justicia señala que deben tenerse en cuenta todos los aspectos analizados y demás las circunstancias que se le acrediten con el fin de determinar si las mismas pueden «suscitar dudas legítimas en el ánimo de los justiciables en cuanto a la impermeabilidad de la Sala Disciplinaria frente a elementos externos, en particular frente a influencias directas o indirectas de los poderes Legislativo y Ejecutivo, y en cuanto a su neutralidad con respecto a los intereses en litigio, y por lo tanto puede dar lugar a una falta de apariencia de independencia o de imparcialidad de dicha sala susceptible de menoscabar la confianza que la Administración de Justicia debe inspirar en los justiciables en una sociedad democrática» (apartado 153). 
La consecuencia de haber constatado que un órgano judicial no es independiente o imparcial, como parece insinuar el Tribunal de Justicia que ocurre en el caso de la Sala Disciplinaria del Tribunal Supremo de Polonia, consiste en la aplicación del principio de primacía del Derecho de la Unión. La primacía implica, en primer lugar, una obligación del juez de intentar una interpretación conforme; y, a continuación de no ser posible la interpretación conforme, el juez nacional debe inaplicar, si fuera necesario y por su propia iniciativa, cualquier disposición contraria de la legislación nacional, aun posterior, sin que deba solicitar o esperar su previa eliminación por vía legislativa o mediante cualquier otro procedimiento constitucional.

Esto significa, a juicio del Tribunal de Justicia, que debe buscarse una solución institucional de sustitución del órgano judicial inhabilitado para aplicar el Derecho de la Unión, por su falta de independencia o imparcialidad, por aquel tribunal que satisfaga las exigencias de independencia e imparcialidad y «que sería competente en el ámbito de que se trate si dicha disposición no se opusiera a ello, es decir, por regla general aquel al que la legislación vigente confería la competencia antes de que tuviera lugar la modificación legislativa que dio lugar a que se atribuyera al órgano que no satisface dichas exigencias» (apartado 166).

Estos avances de la jurisprudencia del Tribunal de Justicia y este acercamiento a Estrasburgo vienen acompañados por un intento de seguir mimando el mismo procedimiento del reenvío prejudicial. El Tribunal de Justicia ha aprobado las nuevas Recomendaciones a los órganos jurisdiccionales nacionales, relativas al planteamiento de cuestiones prejudiciales (DOUE n. ${ }^{\circ}$ C 380 de 8.11.2019, p. 1).

Las anteriores Recomendaciones a los órganos jurisdiccionales nacionales, relativas al planteamiento de cuestiones prejudiciales se habían publicado poco más de un año antes (DOUE n. ${ }^{\circ} \mathrm{C} 257$, de 20.7.2018, p. 1).

Las diferencias con las anteriores Recomendaciones radican en la necesidad de tener en cuenta las transmisiones electrónicas y el reforzamiento de la anonimización. En todo caso no hay duda de que el Tribunal de Justicia insiste en que los jueces nacionales deberían mencionar «las razones que lleven al órgano jurisdiccional remitente a interrogarse sobre la interpretación o la validez del Derecho de la Unión».

\section{Primera parte. Los desarrollos jurisprudenciales del derecho de la Unión Europea}

Siempre como disculpa de la imposibilidad de dar cuenta de todas las decisiones importantes del Tribunal de Justicia, la elección de algunas relevantes se estructura en torno a cuatro ámbitos: los derechos fundamentales, 
el mercado único, el espacio de libertad, seguridad y justicia, y los aspectos institucionales vinculados a la aplicación de las directivas.

\section{Los derechos fundamentales de la Unión}

Con especial celo el Tribunal de Justicia sigue desarrollando los derechos fundamentales en el presente contexto tecnológico. Así lo ha hecho al referirse al derecho al olvido en Internet, el modo de prestar el consentimiento en un entorno tecnológico, la cesación de actos ilícitos en Internet y los datos biométricos de los trabajadores turcos en la Unión.

a) El alcance territorial del derecho al olvido en Internet: sentencia Google France / CNIL

La Gran Sala del Tribunal de Justicia se ha pronunciado sobre el alcance territorial del derecho al olvido en su sentencia Google France / $C N I L$, C-507/17. A preguntas del Consejo de Estado francés, ante el que se planteaba la controversia entre Google y la Comisión Nacional de Informática y Libertades (CNIL), que le había impuesto una sanción de 100.000 euros debido a la negativa de esta sociedad, tras estimar una solicitud de retirada de enlaces de una lista de resultados, a proceder a tal retirada en todas las extensiones de nombre de dominio de su motor de búsqueda.

El Tribunal de Justicia decide interpretar también el Reglamento General de la Protección de Datos, en vigor desde el 25 de mayo de 2018, y realiza un análisis de gran interés de lo que hoy en día es Internet y de las consecuencias que tiene desde el punto de vista del Derecho de la Unión Europea.

En primer lugar, el Tribunal de Justicia comprueba que «Internet es una red mundial sin fronteras y los motores de búsqueda confieren carácter ubicuo a la información y a los enlaces contenidos en una lista de resultados obtenida tras una búsqueda efectuada a partir del nombre de una persona física».

A partir de aquí, el Tribunal de Justicia establece dos principios. Conforme al primero, el Derecho de la Unión no prevé actualmente, tal como resulta del Reglamento General de Protección de Datos, instrumentos ni mecanismos de cooperación sobre el alcance de la retirada de enlaces fuera de la Unión. En cambio, «en principio, la retirada de enlaces de que se trate debe verificarse en todos los Estados miembros, como se desprende en particular del hecho de que el legislador de la Unión haya decidido ahora establecer las normas relativas a la protección de datos mediante un reglamento, de aplicación directa en todos los Estados miem- 
bros, con el fin, como se subraya en el considerando 10 del Reglamento 2016/679, de garantizar un nivel uniforme y elevado de protección en toda la Unión y eliminar los obstáculos a la circulación de datos personales dentro de esta».

Ahora bien, también en este caso, dentro de cada Estado miembro, el Tribunal de Justica establece precisiones de modo que «el interés del público en acceder a una información puede variar, incluso dentro de la Unión, de un Estado miembro a otro, de modo que el resultado de la ponderación que debe llevarse a cabo entre este interés, por un lado, y los derechos al respeto de la vida privada y a la protección de los datos personales del interesado, por otro lado, no será necesariamente el mismo en todos los Estados miembros, máxime cuando, en virtud del artículo 9 de la Directiva 95/46 y del artículo 85 del Reglamento 2016/679, corresponde a los Estados miembros establecer, en particular para los tratamientos realizados exclusivamente con fines periodísticos o con fines de expresión artística o literaria, las exenciones y excepciones necesarias para conciliar esos derechos con, entre otras cosas, la libertad de información».

Esto significa, en definitiva, que «una autoridad de control o judicial de un Estado miembro sigue siendo competente para realizar, de conformidad con los estándares nacionales de protección de los derechos fundamentales [...], una ponderación entre, por un lado, los derechos del interesado al respeto de su vida privada y a la protección de los datos personales que le conciernan y, por otro lado, el derecho a la libertad de información y, al término de esta ponderación, exigir, en su caso, al gestor del motor de búsqueda que proceda a retirar los enlaces de todas las versiones de dicho motor».

Pero también el Tribunal de Justicia subraya la obligación de Google en estos términos: «corresponde al gestor del motor de búsqueda adoptar, en caso necesario, medidas suficientemente eficaces para garantizar la protección efectiva de los derechos fundamentales del interesado. Esas medidas deben respetar en sí todas las exigencias legales y deben tener como efecto impedir o, al menos, dificultar seriamente a los internautas de los Estados miembros el acceso a los enlaces de que se trate mediante una búsqueda efectuada a partir del nombre del interesado».

\section{b) El consentimiento y las cookies en Internet: sentencia Planet49}

La Gran Sala del Tribunal de Justicia se pronuncia en la sentencia Planet49, C-673/17, respondiendo una cuestión prejudicial planteada por el Bundesgerichtshof, el Tribunal Supremo de lo Civil y Penal de Alemania, sobre el consentimiento en materia de datos personales en Internet y las cookies. 
En este caso se planteaba si en la organización por Plantet49 de un juego de apuestas por Internet puede entenderse prestado válidamente el consentimiento mediante una casilla marcada por defecto y de la que el usuario debía retirar la marca en caso de que no desease prestar su consentimiento. En dicha casilla el usuario aceptaba un servicio de análisis de páginas web para lo que se instalarían cookies a quienes se registraban en el juego, lo que permitiría a la empresa analizar el comportamiento de navegación y uso de páginas web de socios publicitarios y enviar publicidad al usuario.

Para ello el Tribunal de Justicia interpreta la Directiva 2002/58/CE sobre la privacidad y las comunicaciones electrónicas en relación con la regulación general de la protección de datos: la Directiva 95/46 y, a partir del 25 de mayo de 2018, el Reglamento 2016/679, el Reglamento General de Protección de Datos

La clave de la respuesta del Tribunal de Justicia está en la previsión de la Directiva sobre la privacidad y las comunicaciones electrónicas conforme a la cual solo se permitirá «el almacenamiento de información, o la obtención de acceso a la información ya almacenada, en el equipo terminal de un abonado o usuario, a condición de que dicho abonado o usuario haya dado su consentimiento después de que se le haya facilitado información clara y completa, en particular sobre los fines del tratamiento de los datos».

A tal efecto, el Tribunal de Justicia llega a la conclusión de que la recogida de datos mediante las cookies constituye un tratamiento de datos personales. Por tanto, su uso requiere el consentimiento del interesado.

El régimen aplicable al consentimiento implica, a juicio del Tribunal de Justicia, una «manifestación» de voluntad del interesado lo que sugiere claramente un comportamiento activo y no pasivo, por lo que «parece prácticamente imposible determinar de manera objetiva si el usuario de un sitio de Internet ha dado efectivamente su consentimiento para el tratamiento de sus datos personales al no quitar la marca de una casilla marcada por defecto y si dicho consentimiento ha sido dado, en todo caso, de manera informada. En efecto, no puede descartarse que dicho usuario no haya leído la información que acompaña a la casilla marcada por defecto, o que ni tan siquiera la haya visto, antes de proseguir con su actividad en el sitio de Internet que visita».

Por tanto, el consentimiento no se presta de manera válida cuando el almacenamiento de información o el acceso a la información ya almacenada en el equipo terminal del usuario de un sitio de Internet se autoriza mediante una casilla marcada por defecto de la que el usuario debe retirar la marca en caso de que no desee prestar su consentimiento.

Por último, el Tribunal de Justicia advierte de que la información que debe proporcionarse sobre las cookies debe incluir el tiempo durante el cual estarán activas y la posibilidad de que terceros tengan acceso a ellas. 
c) Los deberes de cesación de ilícitos en las redes sociales

La sentencia Glawischnig-Piesczek, C-18/18, aborda la cuestión de las obligaciones de Facebook de bloquear o suprimir datos almacenados y declarados judicialmente ilícitos en Austria. El litigio surge como consecuencia de la publicación por Facebook de un comentario que se reputó judicialmente contrario al honor de la diputada austriaca de Los Verdes, Sra. Glawischnig-Piesczek, que intentó que la conocida plataforma mundial de red social eliminara tal comentario.

El Tribunal de Justicia interpreta la Directiva 2000/31/CE sobre el comercio electrónico.

Por una parte, el Tribunal de Justicia considera que Faceboook es un prestador de servicios de alojamiento de datos y determina el alcance de sus responsabilidades. De la Directiva se deduce que las legislaciones nacionales no pueden imponer a Facebook una obligación general de supervisar los datos que transmita o almacene, ni una obligación general de realizar búsquedas activas de hechos o circunstancias que indiquen actividades ilícitas.

Por otra parte, a juicio del Tribunal de Justicia, esta exención no se aplica en los casos específicos, es decir, es legítimo que un tribunal nacional pueda exigir a Facebook que bloquee el acceso a los datos almacenados cuyo contenido sea idéntico al que se ha declarado ilícito con anterioridad, o retire esos datos, sea quien fuere el autor de la solicitud de su almacenamiento. Asimismo, esta obligación se extiende a suprimir los datos a los que se refiera la medida cautelar acordada o a bloquear el acceso a ellos a nivel mundial en el marco del Derecho internacional pertinente.

\section{d) La legalidad de los datos biométricos de trabajadores turcos}

La sentencia Secretario de Estado de Justicia y Seguridad neerlandés / A y otros, C-70/18, se refiere a la legalidad europea del registro de datos biométricos de trabajadores turcos que solicitaban la residencia temporal o la reagrupación familiar en Holanda.

La sentencia responde dos cuestiones: por una parte, si esta normativa holandesa respetaba la obligación de standstill impuesta por los Acuerdos con Turquía; y, por otra parte, cuál era el régimen aplicable a este tipo de registro consistente en diez impresiones dactilares y una imagen facial.

En cuanto a la primera cuestión el Tribunal de Justicia comprueba que, efectivamente, se trata de una nueva restricción; sin embargo, también explica que el objetivo consistente en la prevención y lucha contra la usurpación de identidad y el fraude documental puede constituir una razón imperiosa de interés general susceptible de justificar una «nueva restricción». 
Respecto de la segunda cuestión, los razonamientos del Tribunal de Justicia, fundados en la consagración del derecho a la protección de los datos personales de la Carta, son muy detallados hasta el punto de referirse a los distintos requisitos para que estas medidas sean proporcionadas.

Así, en primer lugar, es necesario comparar las impresiones dactilares del trabajador turco o de las personas que solicitan la reagrupación familiar con las ya recogidas en un fichero central de las autoridades neerlandesas.

En segundo lugar, la toma de los datos biométricos, las huellas dactilares y la imagen facial, permiten identificar de manera fiable a la persona de que se trate, no revisten un carácter íntimo y tampoco suponen un inconveniente físico o psíquico particular para la persona de que se trate, como ya exige el Reglamento General de Protección de Datos a los solicitantes de asilo.

En tercer lugar, esta normativa neerlandesa no es discriminatoria porque se impone a todos los nacionales de terceros países que quieran permanecer en los Países Bajos por un período superior a 90 días o residan ilegalmente.

En cuarto lugar, el uso de tales datos resulta restringido a las autoridades neerlandesas y el plazo de conservación se limita a cinco años por lo que no es excesivo.

Por todo lo cual, el Tribunal de Justicia no solo comprueba que la toma de estos datos biométricos está justificada sino que también es proporcionada.

\section{El mercado único europeo: sentencia Airbnb Ireland}

La libre prestación de servicios en la economía colaborativa digital está poniendo a prueba la realización del mercado único europeo. A las sentencias vinculadas a Google o Uber se une ahora la sentencia Airbnb Ireland, C-390/18, referida a la potente plataforma de alquiler de apartamentos turísticos.

El origen de la cuestión prejudicial es un Juez de Instrucción del Tribunal de París que le preguntaba al Tribunal de Justicia por la aplicación de la Directiva 2000/31 sobre el comercio electrónico al servicio prestado por Airbnb y la respuesta fue afirmativa.

El servicio que presta Airbnb consiste en un servicio que tiene por objeto poner en contacto mediante una plataforma electrónica, a cambio de una remuneración, a potenciales arrendatarios con arrendadores profesionales o no profesionales que ofrecen servicios de alojamiento de corta duración, con el fin de que los primeros puedan reservar un alojamiento. A juicio del Tribunal de Justicia y a diferencia de su jurisprudencia sobre Uber, 
en este caso no hay duda de que se aplica la Directiva sobre el comercio electrónico.

Ahora bien, la fuerza de esta sentencia está en la respuesta a la cuestión de si la legislación francesa restrictiva de la libre circulación de los servicios de la sociedad de la información. La respuesta del Tribunal de Justicia es contundentemente afirmativa de manera que el incumplimiento de la obligación de notificación previa de este tipo de legislaciones nacionales a la Comisión Europea tiene efecto directo. Por tanto, el Tribunal de Justicia se refiere a que la inoponibilidad de una medida no notificada que limite la libre prestación de los servicios de la sociedad de la información que se puede invocar no solo con ocasión de un proceso penal sino también en un litigo entre particulares.

\section{El espacio de libertad, seguridad y justicia para los extranjeros}

El espacio europeo representa una oportunidad para los extranjeros de terceros países y el estatuto de larga duración de estos ciudadanos, regulado por la Directiva 2003/109/CE, constituye un elemento esencial del trato equitativo previsto por los Tratados constitutivos. Sin embargo, no existe propiamente una equiparación entre los estatutos de ciudadano de la Unión y de nacional de terceros países. Asimismo, el Tribunal de Justicia ha establecido límites a los poderes sancionadores de la Administración frente a menores extranjeros no acompañados en instituciones de acogida.

El Tribunal de Justicia ha analizado en su sentencia X / Belgische Staat, C-302/18, el alcance del estatuto de los extranjeros de terceros países residentes de larga duración y a la interpretación del concepto «recursos estables, regulares y suficientes».

Se trataba de un camerunés que llevaba viviendo el Bélgica desde 2007 y que reclamaba el estatuto de residente de larga duración. A la hora de determinar el concepto de recursos en los términos que establece la Directiva 2003/109/CE, el Tribunal de Justicia tuvo en cuenta el régimen de la Directiva 2004/38/CE, relativa a los ciudadanos de la Unión y sus familias por lo que, en principio, no excluye que el interesado pueda hacer valer recursos procedentes de un tercero, que sea miembro de su familia.

Ahora bien, la diferencia entre ambas regulaciones radica, según el Tribunal de Justicia, en la preservación del sistema de asistencia social del Estado miembro de que se trate por lo que los requisitos de «recursos» en el sentido de la Directiva 2003/109 tienen un alcance diferente del que establece la Directiva 2004/38 por lo que el factor decisivo no es la procedencia de los recursos, sino el hecho de que sean duraderos y suficientes, habida cuenta de la situación individual del interesado. 
Por todo lo cual y en este caso, a juicio del Tribunal de Justicia, incumbe a las autoridades belgas analizar en su conjunto la situación individual concreta del camerunés de acuerdo con el estatuto de residente de larga duración y explicar las razones por las que sus recursos son o no suficientes y presentan o no cierta permanencia y cierta continuidad, a fin de que el referido solicitante no se convierta en una carga para Bélgica.

La sentencia Haqbin, C-233/18, pone de manifiesto los límites que la dignidad humana y la condición de persona vulnerable, en este caso un menor afgano no acompañado, frente a los poderes sancionadores administrativos de un centro de acogida belga.

Por haber participado en una reyerta el menor afgano fue expulsado del centro de acogida y privado durante quince días de toda ayuda material por el centro de acogida debiendo vivir en el parque o en casa de unos amigos.

El Tribunal laboral belga le pregunta al Tribunal de Justicia sobre la interpretación de la Directiva 2013/33/UE sobre la acogida de los solicitantes de protección internacional y, en particular, sobre las sanciones que las autoridades nacionales pueden fijar para los casos de violación grave de la normativa aplicable en los centros de acogida, así como para los casos de comportamiento violento grave de los solicitantes de asilo.

El Tribunal de Justicia en su formación de Gran Sala subraya que el respeto de la dignidad humana, consagrado por el artículo 1 de la Carta de los Derechos Fundamentales de la Unión, exige que la persona no se encuentre en una situación de privación material extrema que no le permita hacer frente a sus necesidades más elementales, como alojarse, alimentarse, vestirse y lavarse, y que menoscabe por ello su salud física o mental o la coloque en una situación de degradación incompatible con tal dignidad.

A tal efecto, el Tribunal de Justicia explica el tipo de medidas que podían haberse adoptado contra la vulneración de las normas del centro de acogida: reducir el beneficio de las condiciones materiales de acogida, incluida la retirada o reducción de la asignación para gastos diarios; mantenerlo en una parte separada del centro de acogida, junto con una prohibición de contacto con determinados residentes del centro, o trasladarlo a otro centro de acogida o a otro alojamiento.

Ahora bien y tratándose de un menor no acompañado también ha de tenerse en cuenta que es una personal vulnerable por lo que, de acuerdo con el artículo 24 de la Carta sobre los derechos del niño, debe valorarse el interés superior del menor teniendo especialmente en cuenta factores como su bienestar y desarrollo social, y atendiendo especialmente a su contexto, así como consideraciones relativas a su seguridad y protección.

Por tanto y a la hora de adoptar sanciones, las autoridades nacionales deben tener en cuenta su situación particular y el principio de proporciona- 
lidad, lo que, por ejemplo, no impediría confiarlo a las autoridades administrativas o judiciales encargadas de la protección de la juventud.

\section{La responsabilidad y el control en la transposición de las directivas}

La naturaleza de las normas del Derecho de la Unión Europea y su aplicación constituyen un elemento esencial de la integración europea. En dos sentencias el Tribunal de Justicia se pronuncia sobre los remedios para la mala transposición y por la falta de comunicación de las autoridades nacionales de las medidas de transposición.

a) La sentencia AW, el 112 y la responsabilidad por mala transposición de la Directiva en Lituania

La sentencia $A W$ y otros, C-417/18, se refiere a las posibles consecuencia de la incorrecta incorporación al Derecho lituano de la obligación contenida en la Directiva 2002/22/CE relativa al servicio universal en materia de comunicaciones electrónicas por cuanto obliga a utilizar de forma gratuita el número único europeo de urgencia 112 y a la transmisión a los servicios de emergencia, en la medida en que sea técnicamente posible, de información relativa a la ubicación de las personas que efectúan las llamadas con el fin de mejorar el nivel de protección y seguridad de los usuarios.

En este caso se había reclamado la responsabilidad del Estado lituano como consecuencia del secuestro, violación y quema de una joven de 17 años en el maletero de un automóvil. La joven había llamado diez veces al 112 para pedir socorro sin que el Centro de Atención de Llamadas de Emergencia mostrase el número del teléfono móvil utilizado ni fuese posible localizarla.

El Tribunal de Justicia explica que la Directiva establece una obligación de resultado de modo que no se limita a establecer un marco normativo adecuado, sino que exige que los datos sobre la ubicación de cada llamada al número 112 se transmitan efectivamente a los servicios de emergencia, aunque la llamada se haya hecho desde un teléfono móvil sin tarjeta SIM.

Al mismo tiempo, el Tribunal de Justicia puntualiza que la Directiva, al exigir la transmisión obligatoria de la información relativa a la ubicación de la persona que hace la llamada, pretende mejorar el nivel de protección y la seguridad de los usuarios del número 112, así como ayudar a los servicios de emergencia en el cumplimiento de su misión. Todo ello dentro de los límites de viabilidad técnica, por lo que tal apreciación presenta un carácter eminentemente técnico y está íntimamente ligada a las especificidades de la red de telecomunicaciones móviles lituana. 
Por último, el Tribunal de Justicia se pronuncia sobre los requisitos de la responsabilidad del Estado por violación del Derecho de la Unión. Según el Tribunal de Justicia, «entre los requisitos que deben cumplirse para que se genere la responsabilidad de un Estado miembro por los daños causados a los particulares por violaciones del Derecho de la Unión que le son imputables, figura el relativo a la existencia de una relación de causalidad directa entre la violación de este Derecho y el daño sufrido por estos particulares». Ahora bien, en el supuesto de que, de conformidad con el Derecho lituano, tal como ha sido interpretado por la jurisprudencia de sus órganos jurisdiccionales, una relación de causalidad indirecta se considere suficiente a efectos de generar la responsabilidad del Estado, también debe considerarse suficiente, en virtud del principio de equivalencia, una relación de causalidad indirecta entre una vulneración del Derecho de la Unión imputable al Estado lituano y el daño sufrido por los particulares para generar la responsabilidad de Lituania.

b) Bélgica condenada a una multa coercitiva por no informar sobre la transposición de una Directiva

El Tribunal de Justicia ha condenado, en su sentencia de 8 de julio de 2019, C-543/17, a Bélgica a pagar una multa coercitiva de 5.000 euros diarios dado que, en relación con la Región de Bruselas Capital, no había comunicado las medidas de transposición de la Directiva 2014/61/UE relativa a medidas para reducir el coste del despliegue de las redes de comunicaciones electrónicas de alta velocidad.

El plazo de transposición de la Directiva 2014/61/UE había terminado el 1 de enero de 2016 y la Comisión Europea interpuso el 15 de septiembre de 2017 un recurso por incumplimiento en el que pedía al Tribunal de Justicia que declarase el incumplimiento de Bélgica y le impusiese una multa coercitiva hasta que informase sobre las medidas de transposición de la Directiva.

El Tribunal de Justicia interpreta el nuevo procedimiento establecido en el marco del recurso por incumplimiento del artículo 260.3 TFUE. A juicio del Tribunal de Justicia, el objetivo de este artículo «no es solo incitar a los Estados miembros a poner fin lo antes posible a un incumplimiento que, de no existir dicha medida, tendría tendencia a persistir, sino también agilizar y acelerar el procedimiento para la imposición de sanciones económicas en los casos de incumplimiento de la obligación de informar sobre las medidas nacionales de transposición de una directiva adoptada de conformidad con el procedimiento legislativo, precisándose que, antes de la introducción de tal mecanismo, podían llegar a transcurrir años antes de que se impusiera una sanción económica a los Estados 
miembros que no ejecutaran en los plazos fijados una sentencia anterior del Tribunal de Justicia y que no cumplieran su obligación de transposición» (apartado 52).

Esto significa que al Tribunal de Justicia le corresponde ejercer su función judicial de apreciar, en el marco de un mismo procedimiento, si un Estado ha cumplido las obligaciones que le incumben en materia de información y, en su caso, valorar la gravedad del incumplimiento declarado e imponer la sanción económica que considere más adecuada a las circunstancias del caso.

En el caso concreto, el Tribunal de Justicia comprobó que Bélgica había persistido parcialmente en su incumplimiento al no haber adoptado, al vencer el plazo señalado en el dictamen motivado de la Comisión, las medidas necesarias para transponer, respecto a la Región de Bruselas Capital, la Directiva 2014/61 ni a fortiori había comunicado a la Comisión las medidas de transposición.

Asimismo, corresponde al Tribunal de Justicia determinar, en función de las circunstancias concretas del asunto del que conoce y del grado de persuasión y de disuasión que considere necesario, las sanciones económicas que resulten apropiadas, en particular para evitar la repetición de infracciones análogas del Derecho de la Unión.

Su cuantía la calcula el Tribunal de Justicia en función de la gravedad de la infracción, su duración y la capacidad de pago del Estado miembro de que se trate, teniendo en cuenta las consecuencias de la falta de ejecución sobre los intereses públicos y privados en juego, así como la urgencia que hubiere en que el Estado miembro cumpla sus obligaciones.

Finalmente, la multa coercitiva aplicada a Bélgica es de 5.000 euros que se imponen desde el día en que se dicta la sentencia hasta que termine el incumplimiento.

\section{Segunda parte. La Jurisprudencia Europea provocada por los jueces españoles y sus efectos en el derecho interno}

En esta parte de la Crónica, que se ocupa de manera pormenorizada de los efectos de la jurisprudencia del Tribunal de Justicia en España, no puede faltar una referencia a quienes en Luxemburgo ejercen la discreta función de jueces y, en particular, de quienes desde nuestro país se integran en la más alta judicatura europea.

Pues bien, desde octubre de 2019 se incorporaron al Tribunal General dos extraordinarios juristas españoles: Miguel Sampol Pucurull, abogado del Estado, que fue el anterior Jefe del Servicio Jurídico del Gobierno español ante el Tribunal de Justicia de la Unión Europea, y José Martín y Pérez 
de Nanclares, catedrático de Derecho Internacional Público y anterior Director del Servicio Jurídico del Ministerio de Asuntos Exteriores.

$\mathrm{Al}$ mismo tiempo terminaron su mandato, no sin litigio ante los tribunales españoles, los dos jueces anteriores del Tribunal General, Ignacio Rubio Ulloa, juez de carrera, y Leopoldo Calvo-Sotelo Ibáñez, letrado del Consejo de Estado, cuya trayectoria ha sido notable. Ahora bien, en sendos recursos contencioso-administrativos formulados ante el Tribunal Supremo los sustituidos cuestionaron la legalidad de su cese impuesta por el Gobierno español.

Por el momento, el Tribunal Supremo desestimó la adopción de las medidas cautelares mediante sendos autos de 19 de febrero y 13 de marzo de 2019, Sala 3. a, Sección 4. ${ }^{\text {a }}$, recurso 456/2018, ES:TS:2019:1715A, ponente: Fonseca-Herrero Raimundo; y recurso n. ${ }^{\circ}$ 2/2019, ES:TS:2019:2634A, ponente: Requero Ibáñez.

A continuación se analizan las sentencias más reseñables en este semestre provocadas desde España y que abordan cuestiones como la inmunidad de Oriol Junqueras como eurodiputado, el alcance de la protección social del Derecho de la Unión, la interpretación de la Directiva sobre cláusulas abusivas de los contratos de los consumidores, el sistema tributario español y la protección de las variedades vegetales.

\section{El alcance de la inmunidad de los eurodiputados: sentencia Junqueras}

La Gran Sala del Tribunal de Justicia se ha pronunciado en virtud de la sentencia Junqueras Vies, C-502/19, sobre la adquisición de la condición de eurodiputado y el alcance de su inviolabilidad y de su inmunidad. Esta sentencia responde un reenvío cuestión prejudicial de la Sala de lo Penal del Tribunal Supremo que quería saber de los efectos que tuvo la elección del Sr. Junqueras como miembro del Parlamento Europeo.

El Tribunal Supremo formuló el 1 de julio de 2019 tres preguntas relativas al efecto que tiene la inmunidad de los elegidos al Parlamento Europeo en relación con quien, siendo vicepresidente de la Generalidad de Cataluña, estaba en situación de detención provisional y estaba siendo juzgado por el Tribunal Supremo bajo la acusación de varios delitos graves que había cometido en 2017.

Las elecciones al Parlamento Europeo se habían celebrado el 26 de mayo de 2019 y la proclamación de los resultados se hizo por la Junta Electoral Central el 13 de junio de 2019. No obstante, el 14 de octubre de 2019 el Tribunal Supremo condenó al Sr. Junqueras a una pena de trece años de prisión y de inhabilitación absoluta.

El Tribunal de Justicia se refiere al Parlamento Europeo y enfatiza que «el funcionamiento de la Unión se basa en el principio de la democracia re- 
presentativa, que concreta el valor de democracia mencionado en el artículo 2 TUE». Asimismo, constata que en el procedimiento electoral la proclamación oficial de los resultados electorales es competencia de los Estados miembros. Ahora bien, considera que la condición de eurodiputado se adquiere en el momento en que se proclama electa a una persona oficialmente y, a partir de ese momento, se beneficia de las inmunidades. El contenido de estas inmunidades, que corresponde determinar a las legislaciones nacionales, alcanza a las garantías necesarias para el cumplimiento de la misión del eurodiputado. Estas inmunidades reconocidas a los eurodiputados tienen por objeto garantizar la independencia del Parlamento Europeo en el cumplimiento de su misión. En definitiva, la proclamación como electo del Sr. Junqueras el 13 de junio de 2019 le facultaba para dirigirse sin impedimentos a la primera reunión de la nueva legislatura y tomar posesión de su escaño.

Ahora bien y por lo que se refiere a la inmunidad en caso de prisión provisional, el Tribunal de Justicia le explica al Tribunal Supremo español que si el tribunal nacional estima que debe mantenerse una medida de prisión provisional impuesta a una persona que haya adquirido la condición de miembro del Parlamento Europeo, ha de solicitar a la mayor brevedad al Parlamento Europeo que suspenda la inmunidad reconocida.

En definitiva, la inmunidad de los eurodiputados implica que, desde que son proclamados electos, gozan de inmunidad que no puede verse afectada por la prisión provisional y solo para el caso de que el juez nacional considere necesario mantener la prisión provisional debe solicitar el suplicatorio al Parlamento Europeo.

Estas respuestas tienen consecuencias claras dado que la prohibición decretada por el Tribunal Supremo y que impidió al Sr. Junqueras acudir a la sesión constitutiva del Parlamento Europeo, sin haber tramitado el preceptivo suplicatorio, fue contraria a Derecho y debe resolverse, precisamente, el recurso en el que se inscribe la cuestión prejudicial anulando tal decisión jurisdiccional que le impedía acudir a la sesión constitutiva del Parlamento sin autorización del propio Parlamento Europeo.

En cuanto a los efectos que la sentencia pueda tener en la situación actual de condenado penalmente del Sr. Junqueras, solo el Abogado General Szpunar en sus Conclusiones de 12 de noviembre de 2019 se pronunció claramente señalando dos interpretaciones: una literal y otra sistemática.

Conforme a la interpretación literal del régimen de inmunidades de los eurodiputados, no habría objeción alguna dado que «la sentencia de 14 de octubre de 2019, en combinación con el alcance del auto de 14 de mayo de 2019 [conforme al cual no era necesario solicitar al Congreso de los Diputados la autorización puesto que la elección del Sr. Junqueras Vies se ha- 
bía producido una vez abierto juicio oral en el proceso penal en su contra], tiene como consecuencia que el [Sr. Junqueras], pese a haber sido elegido diputado al Parlamento y [h]aber adquirido esa condición, aunque sin haber podido iniciar el ejercicio efectivo del mandato, ha sido juzgado y condenado penalmente sin que el Parlamento haya tenido oportunidad de pronunciarse sobre la suspensión de su inmunidad parlamentaria o sobre el eventual mantenimiento de la misma» (apartado 102).

Ahora bien, en Abogado General apunta que una interpretación sistemática y teleológica, que tenga en cuenta la evolución del Parlamento Europeo, debería haber dejado también en manos del Parlamento Europeo la decisión sobre la continuación del procedimiento penal contra el Sr. Junqueras.

No hay duda alguna de que corresponde al Tribunal Supremo español decidir al respecto. No obstante, el problema se plantea con mayor acuidad en el caso de los eurodiputados Sres. Puigdemont y Comín a los que se había acusado por los mismos hechos de delitos graves pero que por ahora no han sido juzgados. La decisión sobre la continuación de la orden de detención y su procesamiento parece quedar ahora en manos del Parlamento Europeo.

\section{La protección social de los trabajadores en la jurisprudencia del Tribunal de Justicia}

A instancias de los jueces españoles el Tribunal de Justicia ha dictado varias resoluciones que abordan cuestiones de gran trascendencia en el ámbito social y que permiten profundizar en la consolidación de los derechos de los trabajadores.

a) La aplicación de la Carta en materia social y la sentencia Ortiz Mesonero

La sentencia Ortiz Mesonero, C-366/18, tiene interés porque explica, por una parte, que ha de tenerse cuidado en la formulación de cuestiones prejudiciales y, por otra parte, porque recuerda los límites de la aplicación de la Carta de los Derechos Fundamentales.

El litigio planteado ante el Juzgado de lo Social n. 33 de Madrid se refiere a un trabajador a turnos que solicita horario fijo para ocuparse de dos hijos menores y en este caso el artículo 37.6 del Estatuto de los Trabajadores prevé que quien tenga a su cuidado directo algún menor de doce años o una persona con discapacidad que no desempeñe una actividad retribuida tendrá derecho a una reducción de la jornada de trabajo diaria, con la disminución proporcional del salario entre, al menos, un octavo y un máximo de la mitad de su duración. 
El Juzgado madrileño plantea cuestiones prejudiciales sobre la interpretación de la Carta, de la Directiva 2006/54/CE relativa a la aplicación del principio de igualdad de oportunidades e igualdad de trato entre hombres y mujeres en asuntos de empleo y ocupación, y la Directiva 2010/18/UE por la que se aplica el Acuerdo marco sobre el permiso parental.

En primer lugar, el Tribunal de Justicia inadmite las cuestiones relativas a una hipotética discriminación indirecta por razón de sexo y la aplicación de la Directiva 2006/54.

En segundo lugar, el Tribunal de Justicia limita el examen a la Directiva 2010/18 y a la Carta. Ahora bien, comprueba que la única disposición del Acuerdo marco sobre el permiso parental relativa a la adaptación del horario de trabajo es su cláusula 6.1, a tenor de la cual los Estados miembros o los interlocutores sociales tomarán las medidas necesarias para velar por que los trabajadores, al «reincorporarse del permiso parental», puedan pedir cambios en sus horarios o regímenes de trabajo durante un período determinado de tiempo. Sin embargo, el Sr. Ortiz Mesonero que trabaja a turnos pretende una adaptación de su horario de trabajo para poder trabajar con un horario fijo y no consta que se haya reincorporado de un permiso parental.

En tercer lugar, por lo que se refiere a la Carta, señala el Tribunal de Justicia que sus disposiciones «se dirigen a los Estados miembros únicamente cuando apliquen el Derecho de la Unión». Y, por otra parte, recuerda su jurisprudencia conforme a la cual «cuando una situación jurídica no está comprendida en el ámbito de aplicación del Derecho de la Unión, el Tribunal de Justicia no tiene competencia para conocer de ella y las disposiciones de la Carta eventualmente invocadas no pueden fundar por sí solas tal competencia».

Por eso, el Tribunal de Justicia llega a la conclusión de que, al no ser aplicable la Directiva 2010/18, no procede interpretar los artículos 23 y 33.2 de la Carta.

b) La discapacidad en el ámbito laboral y la sentencia $D W /$ Nobel Plastiques Ibérica

La sentencia DW / Nobel Plastiques Ibérica, C-397/18, se refiere a la interpretación de la Directiva 2000/78/CE sobre igualdad en el empleo en lo que se refiere a la discapacidad.

El litigio se había producido en relación con el despido objetivo de una trabajadora que había sido operada de epicondilitis, junto con otras nueve trabajadoras de la empresa. El Juzgado de lo Social n. 3 de Barcelona planteó varias cuestiones prejudiciales que el Tribunal de Justicia contestó refiriéndose al alcance del concepto de discapacidad y a la justificación de un despido objetivo. 
Por lo que se refiere a la discapacidad, el Tribunal de Justicia tiene en cuenta la Convención de las Naciones Unidas sobre los derechos de las personas con discapacidad, ratificada por la Unión Europea, que establece este concepto en el ámbito laboral: «una limitación de la capacidad derivada, en particular, de dolencias físicas, mentales o psíquicas a largo plazo que, al interactuar con diversas barreras, pueden impedir la participación plena y efectiva de la persona de que se trate en la vida profesional en igualdad de condiciones con los demás trabajadores» (apartado 41). Esto significa que en este concepto se incluyen las discapacidades de nacimiento, las debidas a accidentes y las causadas por una enfermedad. Esto quiere decir que «el estado de salud de una persona con discapacidad que pueda trabajar, aunque solo sea a tiempo parcial, puede, por tanto, entrar dentro del concepto de "discapacidad"»

En cuanto a la justificación del despido objetivo, la empresa había despedido a diez trabajadoras, incluida la que padecía discapacidad, porque respondían a estos cuatro criterios: presentaban una productividad inferior a un determinado nivel, una menor polivalencia en los puestos de trabajo de la empresa y un elevado índice de absentismo.

El Tribunal de Justicia se pregunta si esta trabajadora fue discriminada directa o indirectamente por motivos de discapacidad. Como los criterios se aplicaron de manera igual para todos, no cabe apreciar discriminación directa. Sin embargo, el Tribunal de Justicia comprueba que los criterios establecidos pueden suponer indirectamente una discriminación. Ahora bien, la Directiva obliga a los empresarios a adoptar ajustes razonables, es decir, deberán tomar las medidas adecuadas, en función de las necesidades de cada situación concreta, para permitir a las personas con discapacidades acceder al empleo, tomar parte en el mismo o progresar profesionalmente, o para que se les ofrezca formación, salvo que esas medidas supongan una carga excesiva para el empresario. En consecuencia y de acuerdo con la Convención de la ONU, la discriminación por motivos de discapacidad incluye todas las formas de discriminación, entre ellas la denegación de ajustes razonables. En cambio, si el juez nacional comprueba que el empleador había adoptado las medidas adecuadas y, en consecuencia, había realizado ajustes razonables, no procedería considerar que un despido basado en tales criterios de selección constituía una discriminación indirecta.

c) El empleo público temporal y el alcance de la Directiva 1999/70: auto Aragón Carrasco

El Tribunal de Justicia sigue contestando las reiteradas preguntas de los tribunales españoles sobre la interpretación de la Directiva 1999/70 relativa al Acuerdo marco de la CES, la UNICE y el CEEP sobre el trabajo de duración determinada. 
El auto Aragón Carrasco / Consejo General del Poder Judicial, responde la cuestión prejudicial de la Sala de lo Contencioso-administrativo del Tribunal Supremo en relación con la reclamación de once personas, nombradas personal eventual o de confianza del órgano de gobierno de los jueces, que con motivo de su cese pedían una indemnización en aplicación de las previsiones del Estatuto de los Trabajadores.

Ahora bien, a juicio del Tribunal de Justicia este tipo de empleados eventuales o de confianza «no pueden albergar ninguna expectativa legítima en lo que respecta a la estabilidad de su relación de servicio, dado que son plenamente conscientes, desde el momento de su nombramiento, de la existencia de la posibilidad de ser cesados libremente en sus funciones, así como del hecho de que dicha relación concluirá, a más tardar, al final del mandato de dicha autoridad».

Por tanto, la cláusula 4.1 del Acuerdo Marco no se opone a una normativa española que no prevé el abono de indemnización alguna al personal eventual, que ejerce funciones expresamente calificadas de confianza o asesoramiento especial, con motivo del cese libre en sus funciones, mientras que concede una indemnización al personal laboral fijo con motivo de la extinción de su contrato de trabajo por una causa objetiva.

Preguntado sobre un posible abuso en la contratación de este tipo de personal, tal como prevé la cláusula 5.1 del Acuerdo Marco, el Tribunal de Justicia señala que es aplicable únicamente en el supuesto de sucesivos contratos o relaciones laborales de duración determinada. Sin embargo, estos once casos se caracterizaban por la existencia de una única relación de servicio de cada una de las interesadas por lo que no parece que haya habido abuso alguno.

d) El cálculo de la antigüedad de los trabajadores fijos discontinuos de la Agencia tributaria

El auto OH y ER / AEAT, C-439/18 y C-472/18, responde una cuestión prejudicial planteada por la Sala de lo Social del Tribunal Superior de Justicia de Galicia en relación con la normativa que aplica la Agencia Tributaria a la percepción de trienios por los trabajadores fijos discontinuos, es decir, un colectivo integrado por 898 mujeres y 252 hombres, que realizan trabajos fijos y periódicos dentro del volumen normal de actividad de la Agencia, lo que implica que solo trabajan varios meses al año, por ejemplo durante la campaña de la declaración de la renta de las personas físicas.

El Tribunal de Justicia examina los dos tipos de discriminaciones invocadas: la Directiva 2006/54 que adopta el Acuerdo Marco sobre el Trabajo a Tiempo Parcial y la Directiva 2006/54/CE relativa a la aplicación del principio de igualdad de trato entre hombres y mujeres en asuntos de em- 
pleo, y llega a la conclusión de que existe discriminación entre trabajadores a tiempo parcial y a tiempo completo y entre trabajadores y trabajadoras.

Por una parte y en cuanto se refiere a la discriminación entre trabajadores a tiempo completo y a tiempo parcial, el Tribunal de Justicia subraya que, aun cuando la situación sea comparable, «en el caso de los trabajadores fijos discontinuos, la antigüedad no se computa sobre la misma base, ya que se calcula atendiendo solamente a la duración de los períodos efectivamente trabajados, teniendo en cuenta la reducción de las horas de trabajo».

En el auto se explica claramente el modo de calcular los trienios: un trabajador a tiempo completo adquiere el derecho a un trienio al cabo de un período de empleo de tres años consecutivos, mientras que un trabajador a tiempo parcial requeriría, en el caso de trabajar cuatro meses al año, por lo menos nueve años de relación laboral.

Aun cuando el Gobierno español pretendía aplicar una regla en función del tiempo, pro rata temporis, el Tribunal de Justicia considera que «el Derecho de la Unión no se opone al cálculo de un componente de la retribución conforme a una regla pro rata temporis en caso de trabajo a tiempo parcial»; sin embargo, en el caso de los trienios precisa: «el principio de pro rata temporis no es aplicable a la determinación de la fecha de adquisición de un derecho a un componente de la retribución, en la medida en que esta depende exclusivamente de la duración de la antigüedad adquirida por el trabajador. En efecto, esta antigüedad se corresponde con la duración efectiva de la relación laboral, y no con la cantidad de trabajo realizada durante dicha relación. Por lo tanto, el principio de no discriminación entre trabajadores a tiempo parcial y trabajadores a tiempo completo implica que la duración de la antigüedad tenida en cuenta a efectos de la determinación de la fecha de adquisición de la antigüedad para percibir un trienio se calcule para el trabajador a tiempo parcial como si hubiera ocupado un puesto a tiempo completo, tomando en consideración íntegramente los períodos no trabajados».

En este caso, el Tribunal de Justicia constata la discriminación en la medida en que «los trabajadores a tiempo completo adquieren el derecho a un trienio al cabo de un período de empleo de tres años consecutivos, incluso si en él se incluyen estadios de inactividad, como vacaciones o posibles bajas por enfermedad». En estas circunstancias, resulta discriminatorio el hecho de que, a efectos del cálculo de la antigüedad de los trabajadores fijos discontinuos de la Agencia Tributaria, solo se computen los períodos de trabajo efectivo.

Por otra parte y respecto de la discriminación por razón del sexo, el Tribunal de Justicia constata, tal como le había explicado el Tribunal gallego, que el cálculo de la antigüedad de una trabajadora fija-discontinua tomando en consideración exclusivamente el tiempo efectivamente trabajado, y no el 
de la duración de la relación laboral, está formulado de manera neutra; sin embargo, la medida controvertida en los litigios principales afecta a un número mucho mayor de mujeres que de hombres.

Dado que el Gobierno español no justifica esta discriminación, el Tribunal de Justicia concluye que la regulación aplicable por la Agencia Tributaria en materia de trienios del personal fijo discontinuo es contraria al principio de igualdad entre trabajadoras y trabajadores y no está justificada.

e) La pensión de jubilación anticipada en España y la cotización en Alemania: sentencia Bocero Torrico

El Tribunal de Justicia se pronunció en la sentencia Bocero Torrico, C-398/18 y C-428/18, sobre el caso de dos trabajadores que habían cotizado en España y en Alemania y que vieron denegada la solicitud en nuestro país la pensión por jubilación anticipada por no alcanzar el importe de la pensión que debían percibir el de la pensión mínima.

La sentencia tiene su origen en las cuestiones prejudiciales remitidas desde la Sala de lo Social del Tribunal Superior de Justicia de Galicia conforme a las cuales sería contraria al Derecho de la Unión Europea la legislación española de la Seguridad Social que supedita el derecho a una pensión de jubilación anticipada a que el importe de la pensión a percibir sea superior al importe de la pensión mínima que el interesado tendría derecho a percibir al cumplir la edad legal de jubilación tomando en consideración únicamente la cotización en España.

En efecto, el Tribunal de Justicia acoge este enfoque y considera, en primer lugar, que el Reglamento (CE) n. ${ }^{\circ}$ 883/2004 sobre la coordinación de los sistemas de seguridad social no obliga a los Estados a conceder una pensión de jubilación anticipada a un solicitante cuando su importe no alcance el importe de la pensión mínima que percibiría al cumplir la edad legal de jubilación.

Ahora bien, en segundo lugar, el Tribunal de Justica subraya que el Reglamento consagra el principio de asimilación de prestaciones, de ingresos y de hechos. Esto significa que la regulación española sería contraria a la norma y a la jurisprudencia europeas en la medida en que «la negativa de las autoridades [españolas] a tomar en consideración, a efectos de determinar el derecho a una pensión de jubilación anticipada, las prestaciones de pensión a las que un trabajador que haya hecho uso de su derecho a la libre circulación tiene derecho en [Alemania] puede situar a dicho trabajador en una situación menos favorable que la de un trabajador que haya desarrollado toda su actividad profesional en [España].

En tercer lugar, la regulación española podría justificarse en la medida en que persiga un objetivo de interés general y siempre que sea adecuada 
para garantizar la realización de este y que no vaya más allá de lo necesario para alcanzar el objetivo perseguido; sin embargo, ni el Gobierno español ni el Instituto Nacional de la Seguridad Social han justificado la aplicación discriminatoria de tal requisito en perjuicio de los trabajadores que hayan hecho uso de su derecho a la libre circulación.

El Tribunal de Justicia se pronuncia en su sentencia WA / Instituto Nacional de la Seguridad Social, C-450/18, sobre el complemento de pensión previsto únicamente para las madres. El Juzgado de lo Social n. ${ }^{\circ} 3$ de Gerona cuestionó la concesión de un complemento de pensión, por su aportación demográfica a la Seguridad Social, únicamente a las mujeres que hayan tenido hijos biológicos o adoptados y que sean beneficiarias en cualquier régimen del sistema de la Seguridad Social de pensiones contributivas de jubilación, viudedad o incapacidad permanente, excluyendo de este beneficio a los varones en idéntica situación.

El Tribunal de Justicia comprobó que se trataba de una discriminación directa por razón de sexo y, por lo tanto, está prohibida por la Directiva 79/7/CEE relativa a la aplicación progresiva del principio de igualdad de trato entre hombres y mujeres en materia de seguridad social. Para ello el Tribunal de Justicia sigue los siguientes pasos interpretativos.

En primer lugar, formula el principio de igualdad en el sentido de que «la discriminación consiste en la aplicación de normas diferentes a situaciones comparables o en la aplicación de la misma norma a situaciones diferentes». En el caso concreto comprueba que la situación de madres y padres es comparable, sin perjuicio de reconocer las desventajas profesionales que la maternidad supone para las mujeres; ni las estadísticas que muestran diferencias estructurales entre los importes de las pensiones de las mujeres y las pensiones de los hombres.

En segundo lugar, el Tribunal de Justicia recuerda que una excepción a la prohibición de toda discriminación directa por razón de sexo solo es posible en los casos que se enumeran con carácter exhaustivo en la misma Directiva, como, por ejemplo, las disposiciones relativas a la protección de la mujer en razón de su maternidad.

Ahora bien, en este caso la legislación española no establece ningún vínculo entre la concesión del complemento de pensión y el disfrute de un permiso de maternidad o las desventajas que sufre una mujer en su carrera debido a la interrupción de su actividad durante el período que sigue al parto, hasta el punto de que se concede el complemento también a las mujeres que hayan adoptado dos hijos.

En tercer lugar, el Tribunal de Justicia se refiere a los supuestos en que la Directiva no impide que se excluya la aplicación del principio de igualdad en materia de pensiones a las personas que han educado hijos y a la adquisición del derecho a las prestaciones después de períodos de interrupción 
de empleo debidos a la educación de los hijos. Sin embargo, tales circunstancias no son relevantes en la aplicación del régimen español.

Por último, el Tribunal de Justicia examina la posibilidad de que la legislación española constituya una acción positiva con el fin de mantener o adoptar medidas que ofrezcan ventajas concretas destinadas a facilitar al sexo menos representado el ejercicio de actividades profesionales o a evitar o compensar desventajas en sus carreras profesionales. Sin embargo, el complemento de pensión se limita a conceder a las mujeres un plus en el momento del reconocimiento del derecho a una pensión sin aportar remedio alguno a los problemas que pueden encontrar durante su carrera profesional y no parece que dicho complemento pueda compensar las desventajas a las que estén expuestas las mujeres ayudándolas en su carrera y garantizando en la práctica, de este modo, una plena igualdad entre hombres y mujeres en la vida profesional.

En suma, a juicio del Tribunal de Justicia esta normativa española constituye una discriminación directa por razón de sexo y, por lo tanto, está prohibida por la Directiva 79/7.

\section{La protección de los consumidores frente a las cláusulas abusivas y el poder del juez}

La interpretación de la Directiva 93/13/CEE sobre las cláusulas abusivas en los contratos celebrados con consumidores sigue siendo una inagotable fuente de cuestiones prejudiciales que el Tribunal de Justicia resuelve ya por lo general mediante autos como es el caso de estos tres: auto Bankia / Sánchez Martínez y Sánchez Triviño, C-486/16; auto Bankia / Rengifo Jiménez y Félix Caiza, C-92/16, y auto Banco Bilbao Vizcaya Argentaria I Quintano Ujeta y Sánchez García, C-167/16.

El auto Rengifo Jiménez tiene su origen en el Juzgado de Primera Instancia n..$^{\circ} 6$ de Alicante, se refiere al procedimiento judicial de ejecución y, en particular, resuelve la duda de si es conforme con la Directiva que «un órgano jurisdiccional nacional de primera instancia quede vinculado por una resolución dictada en apelación que ordena que se inicie un procedimiento de ejecución, en atención a la gravedad del incumplimiento de las obligaciones que impone al consumidor el contrato de préstamo hipotecario, y ello a pesar de que ese contrato contenga una cláusula declarada abusiva en una resolución previa que ha adquirido firmeza, pero a la que el Derecho [español] no reconoce fuerza de cosa juzgada».

El Tribunal de Justicia recuerda su jurisprudencia anterior y se centra en dos posibilidades si tras la supresión de la cláusula abusiva el contrato de préstamo hipotecario puede subsistir o no: por una parte, si no puede 
subsistir, el deterioro de la posición procesal de los consumidores afectados, en caso de recurrirse al procedimiento de ejecución ordinaria en lugar de seguir el cauce del procedimiento especial de ejecución hipotecaria, podría justificar que el juez nacional sustituya la cláusula abusiva por la versión de dicha disposición legal posterior a la celebración del contrato controvertido en el litigio principal; por otra parte, si el contrato puede subsistir sin la cláusula abusiva, el juez no la aplicará dicha cláusula, salvo que el consumidor se oponga a ello por considerar que una ejecución hipotecaria le es más favorable que seguir el procedimiento de ejecución ordinaria». En definitiva, el Tribunal de Justicia concluye que no observa que la legislación española sea contraria a la Directiva.

El auto Quintano Ujeta responde la cuestión planteada por el Juzgado de Primera Instancia n. ${ }^{\circ} 2$ de Santander. La respuesta es ambivalente: el Derecho de la Unión se opone «a que una cláusula de vencimiento anticipado de un contrato de préstamo hipotecario declarada abusiva sea conservada parcialmente mediante la supresión, por el juez nacional, de los elementos que la hacen abusiva. Sin embargo, esos artículos no se oponen a que el juez nacional ponga remedio a la nulidad de tal cláusula abusiva, cuya redacción está inspirada en una disposición legal aplicable en caso de convenio de las partes del contrato, sustituyéndola por la nueva redacción de esta disposición legal introducida posteriormente a la celebración del contrato, siempre que el contrato en cuestión no pueda subsistir en caso de supresión de esta cláusula abusiva y la anulación del contrato en su conjunto exponga al consumidor a consecuencias especialmente perjudiciales».

En fin, el auto Sánchez Martínez responde al Juzgado de Primera Instancia n. ${ }^{\circ} 1$ de Fuenlabrada, prácticamente, en los mismos términos, al constatar que la Directiva sobre cláusulas abusivas no se opone a que el juez de instancia quede vinculado por una resolución en apelación que ordena que se inicie un procedimiento de ejecución en atención a la gravedad del incumplimiento de las obligaciones que impone al consumidor el contrato de préstamo hipotecario, y ello a pesar de que ese contrato contenga una cláusula declarada abusiva en una resolución previa que ha adquirido firmeza, pero a la que el Derecho nacional no reconoce fuerza de cosa juzgada.

Por último, la sentencia Bondora, C-453/18 y C-494/18, también se pronuncia sobre las cláusulas abusivas y la potestad del juez a requerimiento de los Juzgados de Primera Instancia n. 11 de Vigo y el n. ${ }^{\circ} 20$ de Barcelona en relación con el Reglamento (CE) n. ${ }^{\circ}$ 1896/2006 relativo al proceso monitorio europeo.

La cuestión clave radica en saber si en el marco de un proceso monitorio europeo el juez pude pedir al acreedor información complementaria relativa a las cláusulas contractuales que este invoca para acreditar la deuda con el fin de controlar de oficio su carácter eventualmente abusivo. 
El Tribunal de Justicia recuerda su jurisprudencia sobre la protección de los consumidores y el hecho de que esta protección se aplica a los procedimientos monitorios nacionales. Por las mismas razones, esa jurisprudencia se aplica en el caso de los monitorios europeos de modo que «el órgano jurisdiccional ante el que se haya presentado una petición de requerimiento europeo de pago debe poder pedir al acreedor información complementaria relativa a las cláusulas que este invoca para acreditar la deuda, como la reproducción de todo el contrato o la presentación de una copia de este, con el fin de poder examinar el carácter eventualmente abusivo de tales cláusulas».

Mediante el auto Bueno Ruiz, C-431/18, el Tribunal de Justicia interpreta, a requerimiento de la Audiencia Provincial de Zaragoza, la Directiva 2009/103/CE relativa al seguro de la responsabilidad civil del automóvil en relación con la reclamación de una vecina contra la titular del vehículo y su aseguradora por la caída producida en el garaje como consecuencia de haber pisado una mancha de aceite procedente de un vehículo.

La interpretación del Tribunal de Justicia es amplia y en el sentido de que está comprendida en el concepto de «circulación de vehículos» de la Directiva una situación en la que un vehículo que ha realizado maniobras o que ha sido estacionado en un garaje privado, conforme a su función de medio de transporte, propicia un accidente acaecido en ese garaje.

\section{El sistema tributario español y el Derecho de la Unión Europea}

Las directivas de armonización de las legislaciones tributarias nacionales tienen un gran impacto en España y, por tanto, su interpretación resulta de extraordinario interés hasta el punto de esgrimirse defensivamente por compañías de gran relevancia pública, como es el caso sistemático de las empresas eléctricas. Asimismo, en un ámbito de unificación legislativa en materia tributaria, como es el caso del Derecho arancelario, resulta de particular relevancia la cuestión relativa a la gestión administrativa de estos recursos propios de la Unión Europea.

a) La impugnación por las compañías eléctricas de los tributos y otras contribuciones

El Tribunal de Justicia ha contestado con dos sentencias del 7 de noviembre de 2019 once reenvíos prejudiciales de la Sala de lo Contencioso-administrativo del Tribunal Supremo donde planteaba, por una parte, la compatibilidad de los impuestos nucleares con la Directiva sobre el mercado europeo de la electricidad, asuntos C-80/18 a C-83/18, UNESA, Endesa Generación e 
Iberdrola Generación Nuclear; y, por otra, la legalidad europea del canon por utilización de las aguas continentales para la producción de energía eléctrica, asuntos C-105/18 a 113/18, UNESA, Engasa y otros.

En los tres asuntos C-80/18 a C-83/18 la Asociación Española de la Industria Eléctrica (UNESA) y otras empresas habían impugnado la Orden HAP/538/2013 sobre autoliquidación de los impuestos sobre la energía nuclear. Los tres recursos contencioso-administrativos fueron desestimados por la Audiencia Nacional.

El Tribunal Supremo planteaba si tal regulación discrimina a la compañías eléctricas porque solo grava a las empresas de generación de electricidad que utilizan energía nuclear y cuyo objetivo principal no consiste en proteger el medio ambiente sino en incrementar el volumen de ingresos del sistema financiero de la energía eléctrica.

El Tribunal de Justicia inadmite, por una parte, las cuestiones relativas a la discriminación de las compañías eléctricas porque la Directiva 2009/72 sobre el mercado interior de la electricidad no constituye una medida de armonización fiscal y, por tanto, no se aplica a la legislación fiscal española sobre la producción y el almacenamiento de combustible y de residuos nucleares. Y tampoco se vulnera el principio de no discriminación de la Carta de derechos fundamentales de la Unión dado que la situación jurídica controvertida no está comprendida en el ámbito de aplicación del Derecho de la Unión. Pero, además y en los casos en que sea aplicable la Directiva, el Tribunal de Justicia considera que las medidas fiscales adoptadas en España no son contrarias a tal Directiva.

Los otros ocho asuntos C-105/18 a 113/18 tienen su origen en sendos recursos contencioso-administrativos de UNESA y otras compañías eléctricas ante la Sala de lo Contencioso-administrativo del Tribunal Supremo por los que se impugnaba el Real Decreto 198/2015 referido a un canon por utilización de las aguas continentales para la producción de energía eléctrica hidráulica.

Las cuestiones prejudiciales preguntaban por la compatibilidad del canon con la Directiva 2000/60/CE sobre la política de aguas y con la Directiva 2009/72/CE del mercado interior de la electricidad y por la aplicación a esta medida del régimen europeo de ayudas de Estado.

Por una parte, el Tribunal de Justicia considera que la Directiva 2000/60/CE no tiene como objetivo una armonización total de las normativas nacionales del agua. Por tanto, la Directiva no impide que el canon hidráulico controvertido se centre en la capacidad de generar ingresos de las compañías hidroeléctricas sin que incentive el uso eficiente del agua, ni establezca mecanismos para la conservación y protección del dominio público hidráulico, ni que su cuantificación se desvincule totalmente de la capacidad de producir daños al dominio público. 
Por otra parte, a juicio del Tribunal de Justicia, el canon no se ve afectado por la Directiva 2009/72 cuyo objetivo es la creación de un mercado interior de la electricidad pero no pretende la armonización de las legislaciones fiscales.

En fin, el Tribunal de Justicia examina si el tributo controvertido constituye una ayuda de Estado y, en primer lugar, inadmite la cuestión prejudicial de si la medida es una ayuda en relación con las empresas no eléctricas que no tienen que abonar el canon. En segundo lugar, el Tribunal de Justicia llega a la conclusión de que la pretendida ayuda no cumple el requisito de la selectividad de las compañías eléctricas cuya energía es de origen hidráulico en relación con aquellas compañías eléctricas con producción no hidroeléctrica.

A tal efecto, el Tribunal de Justicia explica que «la calificación de una medida fiscal de «selectiva» supone, en un primer momento, identificar el régimen tributario común o «normal» aplicable en el Estado miembro de que se trate y, en un segundo momento, demostrar que la medida fiscal en cuestión supone una excepción al referido régimen común, en la medida en que introduce diferenciaciones entre operadores económicos que, con respecto al objetivo asignado a dicho régimen común, se encuentran en una situación fáctica y jurídica comparable» (apartado 61).

Ahora bien, el Tribunal de Justicia considera que el marco de referencia delimitado permiten considerar que los productores de energía hidroeléctrica que operan en una cuenca hidrográfica situada en el interior de una sola comunidad autónoma no se encuentran en una situación comparable a la de los productores de energía que operan en cuencas hidrográficas situadas en el territorio de más de una comunidad autónoma. Y es a estos últimos a quienes se aplica el canon controvertido. Por lo que no se cumpliría en este caso el requisito de la selectividad y la medida fiscal impugnada por las compañías eléctricas no constituiría una ayuda de Estado.

La sentencia Engie Cartagena, C-523/18, se dicta como consecuencia de la impugnación de la Orden ministerial IET/75/2014 sobre transferencias de fondos con cargo a las empresas eléctrica para la ejecución del Plan de Acción de Ahorro y Eficiencia Energética 2011-2020. La Audiencia Nacional remitió desde su Sala de lo Contencioso-administrativo una cuestión prejudicial en la que planteaba si tal regulación, derivada del Real Decreto-ley 14/2010 para la corrección del déficit tarifario del sector eléctrico que introdujo una financiación anual de 270 o 250 millones de euros mediante la aportación porcentual de once compañías eléctricas, era conforme con la Directiva 2009/72/CE sobre normas comunes para el mercado interior de la electricidad. La Audiencia Nacional dudaba de que tal contribución obligatoria constituyese una obligación de servicio público impuesta por el Estado de manera transparente, no dis- 
criminatoria y que garantice a las empresas la igualdad de acceso a los consumidores.

El Tribunal de Justicia llega a la conclusión de que tal contribución obligatoria impuesta a las once compañías eléctricas no es propiamente una obligación de servicio público y para ello explica el contenido de tal concepto.

En primer lugar, el Tribunal de Justicia considera que si tal contribución obligatoria tuviese naturaleza fiscal no se aplicaría la Directiva 2009/72.

En segundo lugar, recuerda que las autoridades nacionales pueden imponer a las empresas eléctricas, en aras del interés económico general, obligaciones de servicio público que podrán referirse a la seguridad, incluida la seguridad del suministro, a la regularidad, a la calidad y al precio de los suministros, así como a la protección del medio ambiente.

Sobre el concepto de obligación de servicio público aplicado a las eléctricas, el Tribunal de Justicia, basándose en las alegaciones de la Comisión Europea, considera que constituye «una intervención pública en el funcionamiento del mercado, con el fin de alcanzar un objetivo de interés económico general, que obliga a las empresas eléctricas a actuar en el mercado sobre la base de criterios impuestos por las autoridades públicas». Esto supone, como desarrolla el Tribunal de Justicia, que la libertad de las empresas para actuar en el mercado de la electricidad es limitada, en el sentido de que, habida cuenta exclusivamente de su interés comercial, dichas empresas no habrían suministrado determinados bienes o servicios, o no lo habrían hecho en la misma medida o en las mismas condiciones.

Esto significa, en definitiva, que a la contribución financiera impuesta a once compañías eléctricas no se le aplican las exigencias de la Directiva 2009/72.

Este cuestionamiento del Derecho español a la luz del Derecho de la Unión Europea tiene otro capítulo especial en el caso de la cuestión prejudicial Viesgo Infraestructuras Energéticas, C-683/19, que acaba de llegar al Tribunal de Justicia precedida por episodios especialmente significativos para la aplicación del Derecho de la Unión Europea en España.

La batalla la planteó la empresa Viesgo Infraestructuras Energéticas al impugnar ante la Sala de lo Contencioso-administrativo del Tribunal Supremo el Real Decreto 968/2014 de fijación de los porcentajes de reparto de las cantidades a financiar relativas al bono social en aplicación del artículo 45 de la Ley del Sector Eléctrico de 2013, que, a su vez, se aprobó de conformidad con la Directiva 2009/72/CE sobre normas comunes para el mercado interior de la electricidad. Esta pequeña compañía eléctrica aducía el carácter discriminatorio del reparto entre 27 compañías eléctricas de la financiación del bono social. 
El Tribunal Supremo, en su sentencia de 24 de octubre de 2016, recurso n. ${ }^{\circ}$ 960/2014, ES:TS:2016:4526, Sala 3. ${ }^{a}$, Sección 3. ${ }^{a}$, ponente: Calvo Rojas, voto particular: Sánchez-Bandrés Cruzat, apreció una contradicción entre la normativa española y la Directiva 20009/72 por lo que inaplica la ley, anula el Real Decreto y reconoce que la compañía eléctrica debe ser indemnizada. En un enérgico voto particular, el magistrado Bandrés SánchezCruzat se opone a esta solución y, en particular, subraya que el reparto de la financiación entre las compañías eléctricas no es discriminatorio y que, en todo caso, habría que plantear la cuestión prejudicial.

La sentencia fue impugnada ante el Tribunal Constitucional que por sentencia 37/2019, de 26 de marzo de 2019, ponente: González-Trevijano Sánchez; voto particular: Ollero Tassara, otorgó el amparo y anuló la sentencia por no haber planteado el Tribunal Supremo la cuestión prejudicial al Tribunal de Justicia. El Tribunal Constitucional expuso una doctrina más que discutible sobre la necesidad de plantear cuestión prejudicial para el caso de inaplicar una ley española. En el voto particular del magistrado Ollero Tassara se pone de manifiesto la situación en que desemboca.

El caso es que el Tribunal Supremo se ha visto obligado a plantear la cuestión prejudicial mediante el auto de 9 de julio de 2019, ES:TS:2019:7922A, con el mismo ponente: Calvo Rojas, y nuevo voto particular de Bandrés Sánchez-Cruzat, registrado en Luxemburgo como Viesgo Infraestructuras Energéticas, C-683/19.

La cuestión prejudicial versa sobre si la financiación del bono social eléctrico tiene carácter discriminatorio entre las compañías eléctricas porque «algunos de esos sujetos obligados tienen muy escaso peso específico en el conjunto del sector, quedando en cambio eximidos de dicha carga otras entidades o grupos empresariales que pueden estar en mejores condiciones para asumir aquel coste».

Así pues, queda en manos del Tribunal de Justicia resolver este enredo que tiene trascendencia en cuanto se refiere al alcance de la potestad del juez para interpretar el Derecho de la Unión Europea, especialmente cuando están en entredicho leyes e incluso normas reglamentarias que el juez entienda contrarias al Derecho de la Unión Europea.

b) La devolución de aranceles abonados sin error imputable a las autoridades aduaneras de terceros países: sentencia Prenatal

La Sala de lo Contencioso-administrativo de Cataluña planteó una cuestión prejudicial de validez al Tribunal de Justicia sobre una decisión aduanera de la Comisión Europea que tenía influencia en las decisiones de las autoridades aduaneras españolas y que fue contestada en sentido negativo por la sentencia Prenatal, C-589/17. 
El litigio contencioso-administrativo se refería a la denegación por la Administración tributaria española de la devolución de aranceles de textiles originarios de Jamaica que en realidad se habían fabricado en China y que, aun cuando inicialmente estaban exentos, finalmente fueron abonados por Prenatal.

Prenatal había importado prendas de vestir a España para lo que había presentado certificados expedidos por las autoridades jamaicanas en los que se mencionaba el origen preferencial de las mercancías en aplicación del Acuerdo de Cotonú de asociación entre la Unión Europea y los Estados de África, del Caribe y del Pacífico (ACP). Sin embargo y como consecuencia de investigaciones de la Oficina Europea de Lucha contra el Fraude (OLAF) se comprobó que las prendas importadas se habían fabricado utilizando componentes importados de China o de Hong Kong, por lo que no podía considerarse que fueran originarias de Jamaica y, en consecuencia, obligaron a Prenatal al pago de los derechos arancelarios.

Este pago al que obligaba la Administración aduanera española se basaba en que la Comisión Europea había decidido en otro caso similar que no procedía conceder la condonación de los derechos de importación solicitada porque, en particular, las autoridades jamaicanas no habían incurrido en ningún error al expedir los certificados aduaneros.

El Tribunal de Justicia en una extensa y compleja sentencia recuerda la obligación de Jamaica, como Estado ACP, de efectuar las oportunas investigaciones para descubrir o evitar transgresiones del régimen aduanero especial cuando existan indicios que hagan sospechar sobre una irregularidad respecto del origen de las mercancías, incluidos los controles físicos; en cambio, cuando no existan tales indicios, las autoridades jamaicanas podían limitarse esencialmente a efectuar controles documentales, y solo de manera ocasional controles físicos (apartados 71 y 72).

El Tribunal de Justicia también considera, frente al reproche de Prenatal, que no puede imputarse a la Comisión haber incumplido su obligación de velar por la correcta aplicación del Acuerdo de Cotonú.

En suma, el Tribunal de Justicia considera que la decisión aduanera de la Comisión Europea es perfectamente válida lo que determina la improcedencia de la solicitud de devolución de ingresos indebidos presentada por Prenatal ante las autoridades aduaneras españolas.

\section{Los derechos derivados de la protección de variedades vegetales}

En la sentencia Club de Variedades Vegetales Protegidas, C-176/18, el Tribunal de Justicia se pronuncia sobre el contenido y el alcance de los derechos de obtenciones vegetales en relación con un litigio del que co- 
noce la Sala Civil del Tribunal Supremo. Se trata de una reclamación del titular del derecho de obtenciones vegetales frente a un agricultor que había adquirido una determinada variedad de mandarinos en un vivero antes de la concesión de la protección por la Oficina Comunitaria de Variedades Vegetales.

El Tribunal de Justicia interpreta el Reglamento (CE) n. ${ }^{\circ}$ 2100/94 relativo a la protección comunitaria de las obtenciones vegetales e indica que, en circunstancias normales, no se aplica al material plantado ni cosechado, sin propagación ulterior, cuando se haya cedido a terceros por el titular o con su consentimiento.

Y por lo que se refiere a los supuestos excepcionales, es decir, cuando no haya habido cesión autorizada, la protección es distinta durante el período provisional, que va desde la publicación de la solicitud de protección, de la que corresponde a la protección registral plena. La operación de referencia es la venta de los plantones.

En el período provisional los frutos obtenidos a partir de los plantones no deben considerarse como obtenidos mediante un empleo no autorizado ni siquiera en el caso de que hayan sido cosechados después de la concesión de la protección comunitaria de obtenciones vegetales.

En el período de protección plena, la venta debe considerarse como no autorizada. Sin embargo, el titular de los derechos podrá reclamar al agricultor siempre y cuando no haya tenido una oportunidad razonable de ejercer ante el vivero sus derechos sobre esos mismos componentes de la variedad.

\section{Relación de las sentencias comentadas}

TJUE, auto, de 12 de junio de 2019, Aragón Carrasco / Consejo General del Poder Judicial, C-367/18, EU:C:2019:487 (cese libre sin indemnización de personal de confianza).

TJUE (Gran Sala), sentencia de 24 de junio de 2019, Comisión / Polonia (reducción de la edad de jubilación de los jueces del Tribunal Supremo), C-619/18, EU:C:2019:531.

TJUE, auto de 3 de julio de 2019, Bankia / Rengifo Jiménez y Félix Caiza, C-92/16, EU:C:2019:560 (cláusulas abusivas y procedimiento ejecutivo).

TJUE, auto de 3 de julio de 2019, Banco Bilbao Vizcaya Argentaria / Quintano Ujeta y Sánchez García, C-167/16, EU:C:2019:570 (cláusulas abusivas y procedimiento ejecutivo).

TJUE, auto de 3 de julio de 2019, Bankia / Sánchez Martínez y Sánchez Triviño, C-486/16, EU:C:2019:572 (cláusulas abusivas y procedimiento ejecutivo).

TJUE (Gran Sala), sentencia de 8 de julio de 2019, Comisión Europea / Bélgica (sanción pecuniaria por no transposición de una directiva), C-543/17, EU:C:2019:573. 
TJUE, sentencia de 29 de julio de 2019, Prenatal / Tribunal Económico Administrativo Regional de Cataluña, C-589/17, EU:C:2019:631 (denegación de la devolución de aranceles de textiles declarados como originarios de Jamaica pero fabricado en China).

TJUE, sentencia de 5 de septiembre de 2019, AW y otros / Lietuvos valstybè, C.417/18, EU:C:2019:671 (responsabilidad por la incorrecta transposición de la Directiva sobre llamada al 112).

TJUE, sentencia de 11 de septiembre de 2019, DW / Nobel Plastiques Ibérica, C-397/18, EU:C:2019:703 (discapacidad y discriminación indirecta en el ámbito laboral).

TJUE, sentencia de 18 de septiembre de 2019, José Manuel Ortiz Mesonero / UTE Luz Madrid Centro, C-366/18, EU:C:2019:757 (trabajador a turnos que solicita horario fijo para ocuparse de dos hijos menores).

TJUE (Gran Sala), sentencia de 24 de septiembre de 2019, Google / Comisión Nacional de Informática y Libertades de Francia (CNIL), C-507/17, EU:C:2019:772 (alcance territorial del derecho al olvido en Internet).

TJUE (Gran Sala), sentencia de 1 de octubre de 2019, Planet49, C-673/17, EU:C:2019:801 (consentimiento sobre datos personales en Internet y cookies).

TJUE, sentencia de 3 de octubre de 2019, Eva Glawischnig-Piesczek / Facebook Ireland Limited, C-18/18, EU:C:2019:821 (obligaciones de una red social de bloquear o suprimir datos declarados judicialmente ilícitos).

TJUE, sentencia de 3 de octubre de 2019, Staatssecretaris van Justitie en Veiligheid / A y otros, C-70/18, EU:C:2019:823 (registro de datos biométricos de trabajadores turcos).

TJUE, sentencia de 4 de octubre de 2019, X / Belgische Staat, C-302/18, EU:C:2019:830 (residentes de larga duración y recursos suficientes de los extranjeros de terceros países).

TJUE, auto de 15 de octubre de 2019, OH y ER / AEAT, C-439/18 y C-472/18, EU:C:2019:858 (cálculo de la antigüedad de los trabajadores fijos discontinuos de la Agencia tributaria).

TJUE (Gran Sala), sentencia de 5 de noviembre de 2019, Comisión / Polonia (independencia y jubilación de los jueces ordinarios y los fiscales), C-192/18, EU:C:2019:924.

TJUE, sentencia de 7 de noviembre de 2019, UNESA, Endesa Generación e Iberdrola Generación Nuclear, C-80/18 a C-83/18, EU:C:2019:934 (impuestos nucleares españoles compatibles con la Directiva sobre el mercado de la electricidad).

TJUE, sentencia de 7 de noviembre de 2019, UNESA, Engasa, Duerocanto, Acciona, Associació de Productors i Usuaris d'Energia Elèctrica, Burgos Pérez y Guinea Bueno, Endesa Generación, APPA y Parc del Segre y otros, C-105/18 a 113/18, EU:C:2019:935 (canon hidráulico a las compañías eléctricas).

TJUE (Gran Sala), sentencia de 12 de noviembre de 2019, Zubair Haqbin / Agencia Federal para la Acogida de los Solicitantes de Asilo de Bélgica, C-233/18, EU:C:2019:956 (límites a las sanciones administrativas a menores no acompañados en los centros de acogida de refugiados). 
TJUE (Gran Sala), sentencia de 19 de noviembre de 2019, A. K. y otros / Tribunal Supremo de Polonia (Independencia de la Sala Disciplinaria del Tribunal Supremo), C-585/18, C-624/18 y C-625/18, EU:C:2019:982.

TJUE, sentencia de 5 de diciembre de 2019, Antonio Bocero Torrico / Instituto Nacional de la Seguridad Social y Tesorería General de la Seguridad Social, y Jörg Paul Konrad Fritz Bode / Instituto Nacional de la Seguridad Social y Tesorería General de la Seguridad Social, C-398/18 y C-428/18, EU:C:2019:1050 (pensión de jubilación anticipada en España y períodos cotizados en Alemania).

TJUE, auto de 11 de diciembre de 2019, Bueno Ruiz y Zurich Insurance / Conte Sánchez, C-431/18, EU:C:2019:1082 (responsabilidad derivada de accidente propiciado por vehículo estacionado en un garaje).

TJUE, sentencia de 12 de diciembre de 2019, WA / Instituto Nacional de la Seguridad Social, C-450/18, EU:C:2019:1075 (complemento de pensión solo para las madres).

TJUE (Gran Sala), sentencia de 19 de diciembre de 2019, Airbnb Ireland, C-390/18, EU:C:2019:1112, (libre prestación de los servicios de la sociedad de la información y el efecto directo de la obligación de notificar normas nacionales).

TJUE (Gran Sala), sentencia de 19 de diciembre de 2019, Junqueras Vies, C-502/19, EU:C:2019:1115 (condición de europarlamentarios e inmunidad penal).

TJUE, sentencia de 19 de diciembre de 2019, Bondora, C-453/18 y C-494/18, EU:C:2019:1118 (cláusulas abusivas y potestad del juez).

TJUE, sentencia de 19 de diciembre de 2019, Engie Cartagena / Ministerio para la Transición Ecológica, C-523/18, EU:C:2019:1129 (financiación del plan de ahorro y eficiencia energética por compañías eléctricas).

TJUE, sentencia de 19 de diciembre de 2019, Club de Variedades Vegetales Protegidas / Adolfo Juan Martínez Sanchís, C-176/18, EU:C:2019:1131 (protección europea de las obtenciones vegetales). 


\section{Derechos de autor}

Los derechos de autor (para la distribución, comunicación pública, reproducción e inclusión en bases de datos de indexación y repositorios institucionales) de esta publicación (Cuadernos Europeos de Deusto, CED) pertenecen a la editorial Universidad de Deusto. El acceso al contenido digital de cualquier número de Cuadernos Europeos de Deusto es gratuito inmediatamente después de su publicación. Los trabajos podrán leerse, descargarse, copiar y difundir en cualquier medio sin fines comerciales y según lo previsto por la ley; sin la previa autorización de la Editorial (Universidad de Deusto) o el autor. Así mismo, los trabajos editados en CED pueden ser publicados con posterioridad en otros medios o revistas, siempre que el autor indique con claridad y en la primera nota a pie de página que el trabajo se publicó por primera vez en CED, con indicación del número, año, páginas y DOI (si procede). Cualquier otro uso de su contenido en cualquier medio o formato, ahora conocido o desarrollado en el futuro, requiere el permiso previo por escrito del titular de los derechos de autor.

\section{Copyright}

Copyright (for distribution, public communication, reproduction and inclusion in indexation databases and institutional repositories) of this publication (Cuadernos Europeos de Deusto, CED) belongs to the publisher University of Deusto. Access to the digital content of any Issue of Cuadernos Europeos de Deusto is free upon its publication. The content can be read, downloaded, copied, and distributed freely in any medium only for non-commercial purposes and in accordance with any applicable copyright legislation, without prior permission from the copyright holder (University of Deusto) or the author. Thus, the content of CED can be subsequently published in other media or journals, as long as the author clearly indicates in the first footnote that the work was published in CED for the first time, indicating the Issue number, year, pages, and DOI (if applicable). Any other use of its content in any medium or format, now known or developed in the future, requires prior written permission of the copyright holder. 